\title{
The effectiveness of selected decontamination techniques in the process of decontamination of chemical protection suits used by chemical rescue units in Fire Service
}

\author{
Zdzisław Salamonowicz ${ }^{1,}$, , Rafał Matuszkiewicz ${ }^{1}$, Małgorzata Ciuka-Witrylak ${ }^{1}$, Dariusz \\ Baranowski $^{1}$, Jacek Chrzęstek ${ }^{1}$, Stanisław Biedugnis ${ }^{1}$ \\ ${ }^{1}$ The Main School of Fire Service, Faculty of Fire Safety Engineering, 52/54 Slowackiego St., \\ 01-629 Warsaw, Poland
}

\begin{abstract}
The paper presents research of the process of decontamination of chemical protection suits. The results of the research show the effectiveness of selected decontamination techniques. In experiments took into account the influence of the contaminant, the time of decontamination, the type of the decontamination agent and the use of mechanical support in removing the contaminant. The research has shown how to minimize the negative action of hazardous substances on protective clothing and show the problem of the possibility of secondary contamination. They demonstrate the impact of each factors on the quality of decontamination and showed that small changes in the process of decontamination significantly affect the safety of the rescuer. The key to effective decontamination is the synergy effect of the studied parameters. This approach will allow efficient and effective execution of the decontamination process, minimize the risk of contact between rescuers and the contaminant and prevent secondary contamination.
\end{abstract}

\section{Introduction}

The increasing threat from terrorist organizations as well as the persistent high level of conflicts between states increases the likelihood of a large scale chemical attack [1-5]. A large group of events are those of a chemical nature, be it in industrial plants or in transport [6-12]. In chemical events rescuers use protective equipment that protects them from the harmful effects of chemical substances, allowing them to work in a dangerous zone [13-19]. Wearing a protective suit or respirator, the rescuer must be confident and trustful about the technical condition and reliability of the equipment [20-27]. To make it possible, the equipment during any rescue operation involving hazardous substances must be properly decontaminated [28-37]. The decontamination process allows the rescuer to safely remove protective clothing exposed to a hazardous substance and reduce the risk of secondary contamination [23-28].

\footnotetext{
*Corresponding author: zsalamonowicz@sgsp.edu.pl
} 
The aim of the research was to measure the effectiveness of various methods of decontamination of a rescuer at chemical events using substances with acidic and alkaline properties. During the tests, the focus was on finding the best result of decontamination with the same input factors as possibly closest to those that may occur in real events [2933]. The intention was to decontaminate the rescuer in each trial in the same way, in the same places of protective clothing and the same amount of contaminant [34-40]. For research purposes, a decontamination cabin from a chemical rescue vehicle was used [4147].

\section{Material and methods}

For research purposes, a decontamination cabin from a chemical rescue vehicle was used (Fig. 1).

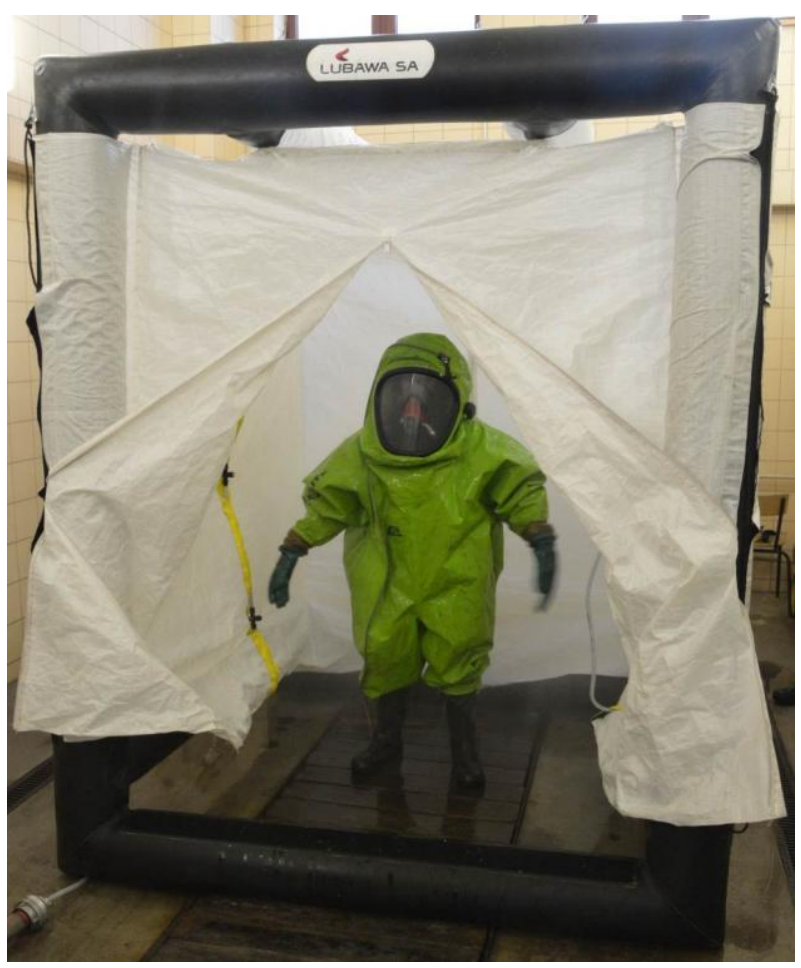

Fig. 1. A rescuer in a decontamination cabin during the decontamination process.

The first six trials were performed using a UV marker as a contaminant. Trials No. 7-12 were carried out using hydrochloric acid as a contaminant. While, tests 13-18 were performed using sodium hydroxide as a contaminant.

\section{Results}

After passing the rescuer through the decontamination cabin, the emission of the UV marker light decreased slightly (Fig. 2). In places where the clothes are wrinkled, the marker's emission has not changed. The quality of decontamination is the same everywhere. At 90 seconds of decontamination, the marker emission decreased to about $40 \%$. The biggest changes were noted on the air apparatus cover, while the smallest ones in the clothes undulations. The third test with the addition of mechanical removal of 
contamination during 30 seconds by scrubbing, reduced the UV marker light emission to an average of $50 \%$. The most effective was the removal from flat surfaces, i.e. the sleeve, while the emission of the UV marker light decreased slightly in the folds of the clothes. Extending the time up to 90 seconds with mechanical scrubbing improved the decontamination process and the UV marker light emission in the clothing folds decreased to $20 \%$. Subsequent tests with the addition of sodium hypochlorite in the decontamination process improved efficiency. During 30 seconds, the UV marker light emission was reduced to an average of $30 \%$, whereas at the time of 90 seconds tracer marks remained only in the gluing cavities of individual pieces of clothing and in hardly accessible folds (Fig. 3).

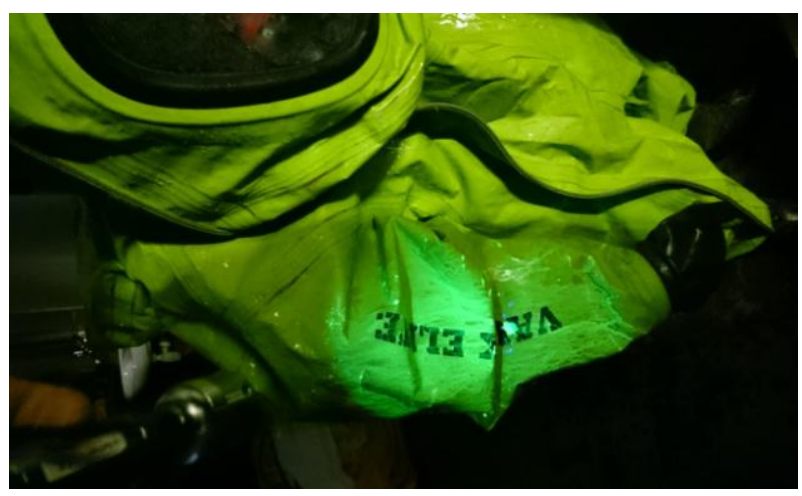

Fig. 2. Test result 1 - decontamination cabin + water - 30seconds.

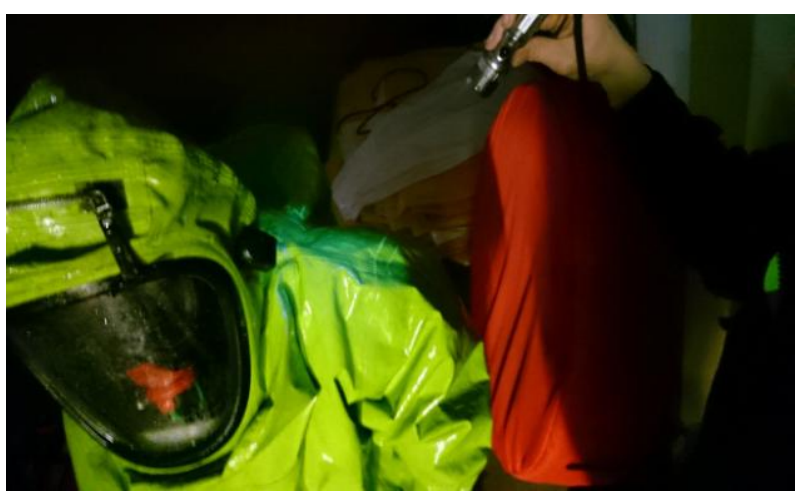

Fig. 3. Test result 6 - decontamination cabin + water + brush + sodium hypochlorite -90 seconds.

Subsequent trials No. 7-12 were carried out using hydrochloric acid as a contaminant. The individual tests were carried out in the same order as with the UV marker. The effectiveness of the decontamination process was estimated based on the $\mathrm{pH}$ read from indicator papers placed in the contamination sites. The average $\mathrm{pH}$ value in the first test with hydrochloric acid was around 5.5. The prolongation of time caused a drop in acidity and the $\mathrm{pH}$ was on average 6 . Addition of mechanical contamination of the contaminant improved the quality of the decontamination process and samples with decontamination times of 30 seconds and 90 seconds achieved average $\mathrm{pH}$ values of 6 and 6.5 , respectively. In subsequent tests with the addition of sodium hypochlorite, also in the folds of clothes, satisfactory results were obtained - the $\mathrm{pH}$ was in folds 6.5 and 7. Only in the area of gluing seams, places with a $\mathrm{pH}$ value of 5 appeared. (Fig. 4). 


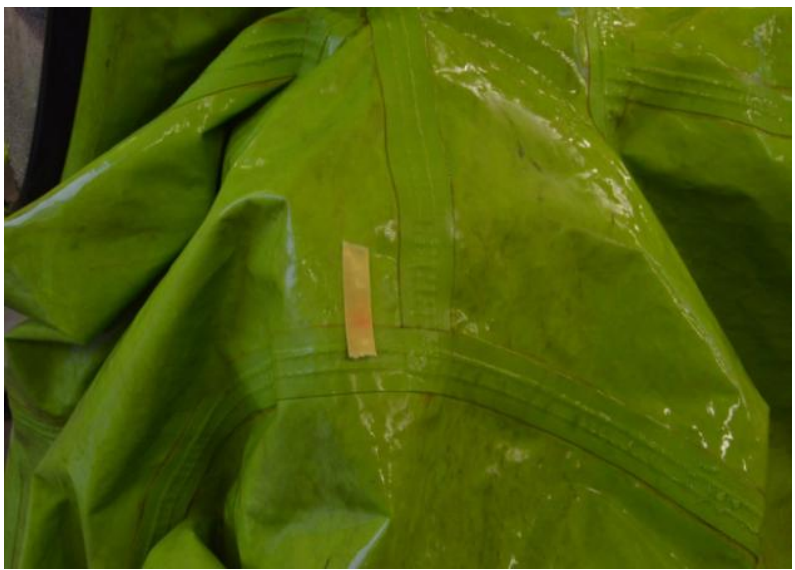

Fig. 4. Test result 12 - decontamination cabin + water + brush + sodium hypochlorite -90 seconds.

Tests 13-18 were performed using sodium hydroxide as a contaminant. The best result was achieved with the addition of mechanical removal with the simultaneous use of sodium hypochlorite. the average $\mathrm{pH}$ in various places was 7.5 (Fig. 5).

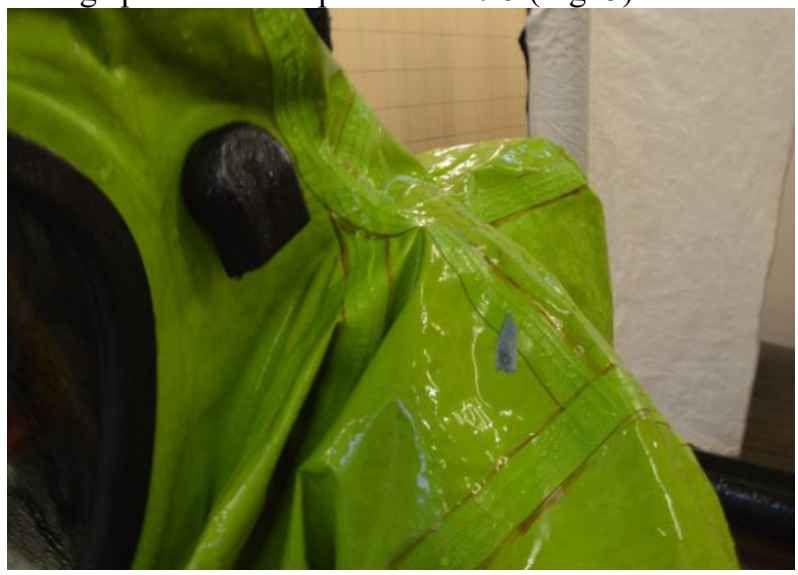

Fig. 5. The result of the test 18 - decontamination cabin + water + brush + sodium hypochlorite -90 seconds.

Table 1 presents a comprehensive summary of the results obtained for all 18 experiments.

Table 1. A summary of the results of the experiments.

\begin{tabular}{|c|c|c|c|c|c|c|}
\hline $\begin{array}{c}\text { Contaminant } \\
\text { [result } \\
\text { parameter] }\end{array}$ & \multicolumn{2}{|c|}{$\begin{array}{c}\text { Decontamination cabin } \\
\text { + water }\end{array}$} & \multicolumn{2}{|c|}{$\begin{array}{c}\text { Decontamination cabin } \\
\text { + water + brush }\end{array}$} & \multicolumn{2}{|c|}{$\begin{array}{c}\text { Decontamination cabin } \\
\text { + water + brush + } \\
\text { sodium hypochlorite } \\
\text { solution }\end{array}$} \\
\hline Time & $30 \mathrm{~s}$ & $90 \mathrm{~s}$ & $30 \mathrm{~s}$ & $90 \mathrm{~s}$ & $30 \mathrm{~s}$ & $90 \mathrm{~s}$ \\
\hline $\begin{array}{c}\text { UV Marker } \\
{[\text { emissivity] }}\end{array}$ & $70 \%$ & $40 \%$ & $50 \%$ & $20 \%$ & $30 \%$ & $<10 \%$ \\
\hline $\begin{array}{c}\mathrm{HCl} \\
{[\mathrm{pH}]}\end{array}$ & 5,5 & 6 & 6 & 6,5 & 6,5 & 7 \\
\hline $\begin{array}{c}\mathrm{NaOH} \\
{[\mathrm{pH}]}\end{array}$ & $>9$ & $>9$ & $>9$ & 8,5 & $>9$ & 7,5 \\
\hline
\end{tabular}




\section{Conclusions}

The effectiveness of decontamination is an extremely important element of the rescue operations that ensure the safety of rescuers participating in the incident. Well-made decontamination will avoid secondary contamination in the parent unit and protect against additional costs of utilization or in extreme cases of equipment recovery.

The key to effective decontamination is the synergy effect of several components: the duration of decontamination, the means for decontamination and the use of equipment for mechanical removal of the contaminant. The combination of the indicated elements allows for efficient and effective execution of the decontamination process, protects against secondary contamination and, above all, minimizes the risk of contact between rescuers and the contaminant. The main factor affecting the quality of decontamination is time. Each attempt within 30 seconds ended in failure of decontamination. This is due to the lack of sufficient amount of the decontamination agent. Additionally, during 30 seconds a rescuer who carries out the process of decontamination cannot manage to clean protective clothing with a brush or spray it with a decontamination agent. Comparing the samples within 30 seconds, adding a brush or sodium hypochlorite solution to the process of decontamination has a positive effect on the final result of decontamination. Comparing the samples within 90 seconds, the results confirm that the use of a brush and sodium hypochlorite solution maximizes the effectiveness of decontamination.

When carrying out decontamination, special attention should be paid too hard to reach places - bends, folds, breaks of protective clothing. During the research, it was discovered that the contamination agent, despite the effective decontamination on the surface of the clothing, accumulates in the sutures of clothing seams, which in consequence in real conditions of use leads to structural contamination.

The most effective decontamination was on the sleeve. This was caused by the best access of the rescuer, who led the process of decontamination to this part of the clothing, the vertical orientation of the decontaminated surface and the minimum number of folds or folds. The worst decontamination effectiveness was on the arm. It was caused by a large number of folds and folds of protective clothing. A good solution in the used decontamination cabin were the sleeves that enable the rescuer to be decontaminated from behind the cabin wall. However, this solution has a disadvantage. Sleeves placed at the chest level, prevent effective decontamination of the lower parts of protective clothing. The solution to this problem was to use a brush with a long handle, which in addition to improving the quality of decontamination itself, served as an extension of the hand of the rescuer, which enabled effective decontamination of the entire garment.

As the minimum time of spraying in the decontamination cabin should be taken 90 seconds. It seems that this is quite a short time, however with blind trials the average time of this process performed by rescuers was about 15-20 seconds. It is therefore reasonable to supervise the process of decontamination by the security officer with measuring the minimum decontamination time per rescuer.

\section{References}

1. Z. Salamonowicz, W. Jarosz, BiTP, 3 (2012)

2. M. Wlodarczyk, A. Sobolewska-Wlodarczyk, A. I. Cygankiewicz, D. Jacenik, A. Piechota-Polanczyk, K. Stec-Michalska, W. M. Krajewska, J. Fichna, M. WisniewskaJarosinska, J. Gastrointestin. Liver Dis., 26 (2017)

3. M. Salaga, L. V. Blomster, A. Piechota-Polanczyk, M. Zielinska, D. Jacenik, A. I. Cygankiewicz, W. M. Krajewska, J. D. Mikkelsen, J. Fichna, J. Pharmacol. Exp. Ther., 356 (2016) 
4. A. Piechota-Polanczyk, S. Demyanets, O. Nykonenko, I. Huk, M. Mittlboeck, C. M. Domenig, C. Neumayer, J. Wojta, J. Nanobachvili, M. Klinger, Eur. J. Vasc. Endovasc. Surg., 45 (2013)

5. A. Polanczyk, A. Piechota-Polanczyk, L. Stefanczyk, PlosOne, 12 (2017)

6. A. Polanczyk, M. Podyma, L. Trebinski, J. Chrzastek, I. Zbicinski, L. Stefanczyk, PLoS One, 11 (2016)

7. M. Salaga, U. Lewandowska, D. Sosnowska, P. K. Zakrzewski, A. I. Cygankiewicz, A. Piechota-Polanczyk, M. Sobczak, P. Mosinska, C. Chen, W. M. Krajewska, J. Fichna, Naunyn Schmiedeberg's Arch. Pharmacol., 387 (2014)

8. A. Piechota-Polanczyk, M. Wlodarczyk, A. Sobolewska-Wlodarczyk, M. Jonakowski, A. Pilarczyk, K. Stec-Michalska, M. Wisniewska-Jarosinska, J. Fichna, Dig. Dis. Sci., 62 (2017)

9. Z. Salamonowicz, M. Kotowski, M. Polka, W. Barnat, Przem. Chem., 93 (2014)

10. Z. Salamonowicz, M. Wolinski, M. Sobolewski, M. Polka, Przem. Chem., 93 (2014)

11. Z. Salamonowicz, M. Majder-Lopatka, BiTP, 30 (2013)

12. A. Dmochowska. Wars. Univ. Tech. Pub. (2009)

13. A. Polanczyk, M. Podgorski, T. Wozniak, L. Stefanczyk, M Strzelecki, Medicina, 54, 15 (2018)

14. W. Jarosz, Z. Salamonowicz, M. Majder-Lopatka, R. Matuszkiewicz, A. Dmochowska, Przem. Chem., 93 (2014)

15. M. Polka, Z. Salamonowicz, M. Wolinski, B. Kukfisz, Procedia Eng., 45 (2012)

16. A. Polanczyk, M. Podyma, L. Stefanczyk, W. Szubert, I. Zbicinski, J. Biomech., 48 (2015)

17. W. Eilenberg, S. Stojkovic, A. Piechota-Polanczyk, C. Kaun, S. Rauscher, M. Groger, M. Klinger, J. Wojta, C. Neumayer, I. Huk, S. Demyanets, Eur. J. Vasc. Endovasc. Surg., 51 (2016)

18. H. Zatorski, M. Salaga, M. Zielinska, A. Piechota-Polanczyk, K. Owczarek, R. Kordek, U. Lewandowska, C. Chen, J. Fichna, Naunyn Schmiedeberg's Arch. Pharmacol., 388 (2015)

19. A. Polanczyk, M. Strzelecki, T. Wozniak, W. Szubert, L. Stefanczyk, Foundations of Computing and Decision Sciences, 42, 13 (2017)

20. D. Dmochowski, A. Dmochowska, S. Biedugnis, ROS, 17 (2015)

21. A. Piechota-Polanczyk, M. Zielinska, D. Piekielny, J. Fichna, Biomed. Pharmacother., 84 (2016)

22. A. Polanczyk, A. Piechota-Polanczyk, C. Domenig, J. Nanobachvili, I. Huk, C. Neumayer, Appl. Sci. 8, 14 (2018)

23. A. Polanczyk, M. Klinger, J. Nonobachvili, I. Huk, C. Neumayer, Appl. Sci., 8, 12 (2018)

24. A. Polanczy, T. Wozniak, M. Strzelecki, W. Szubert, L. stefanczyk, Signal Processing SPA, 5 (2016)

25. A. Zieminska-Stolarska, A. Polanczyk, I. Zbicinski, J. Hydrol. Hydromech., 644, 8 (2015)

26. M. Majder-Lopatka, W. Rogula-Kozlowska, W. Wasik, E3S Web of Conferences, 44 (2018)

27. A. Piechota, A. Polanczyk, A. Goraca, Pharmacol. Rep., 62 (2010)

28. M. Majder-Lopatka, T. Wesierski, E3S Web of Conferences, 46 (2018)

29. M. Majder-Lopatka, T. Wesierski, W. Wasik, BiTP, 42, 8 (2016)

30. A. Piechota-Polanczyk, A. Jozkowicz, Curr. Drug Targets, 17 (2016)

31. A. Polanczyk, M. Podgorski, M. Polanczyk, N. Veshkina, I. Zbicinski, L. Stefanczyk, C. Neumayer, Interact. Cardiovasc. Thorac. Surg. (2018)

32. A. Polanczyk, P. Wawrzyniak, I. Zbicinski, Drying Technol., 31, 10 (2013) 
33. P. Wawrzyniak, A. Polanczyk, I. Zbicinski, M. Jaskulski, M. Podyma, J. Rabaeva, Drying Technol., 30, 10 (2012)

34. Z. Salamonowicz, R. Makowski, E3S Web of Conferences, 44 (2018)

35. P. Wawrzyniak, M. Podyma, I. Zbicinski, Z. Bartczak, A. Polanczyk, J. Rabaeva, Drying Technol., 30, 9 (2012)

36. A. Piechota, A. Goraca, J. Physiol. Pharmacol., 62 (2011)

37. Z. Salamonowicz, M. Kotowski, M. Polka, W. Barnat, Bull. Pol. Ac.: Tech. 63 (2015)

38. A. Polanczyk, Z. Salamonowicz, E3S Web of Conferences, 44, 8 (2018)

39. D. Dmochowski, A. Dmochowska, S. Biedugnis, ROS, 17 (2015)

40. A. Polanczyk, M. Podyma, L. Stefanczyk, I. Zbicinski, Chem. Eng. Process., 33, 9 (2012)

41. T. Wesierski, M. Majder-Lopatka, R. Matuszkiewicz, R. Porowski, Przem. Chem., 91, $3(2012)$

42. A. Piechota-Polanczyk, A. Goraca, Pharmacol. Rep., 64 (2012)

43. A. Piechota, A. Polanczyk, A. Goraca, Pharmacol. Rep., 63 (2011)

44. A. Piechota-Polanczyk, A. Kopacz, D. Kloska, B. Zagrapan, C. Neumayer, A. Grochot-Przeczek, I. Huk, C. Brostjan, J. Dulak, A. Jozkowicz, Oxid. Med. Cell Longev., 2018 (2018)

45. K. Kowalska, D. E. Habrowska-Gorczynska, C. Neumayer, M. Bolliger, C. Domenig, A. W. Piastowska-Ciesielska, I. Huk, A. Piechota-Polanczyk, Acta Biochim. Pol., 65, 1 (2018)

46. D. Kloska, A. Kopacz, A. Piechota-Polanczyk, W. Nowak, J. Dulak, A. Jozkowicz, A. Grochot-Przeczek, Vascul. Pharmacol. (2018) (to be published)

47. T. Wesierski, M. Majder-Lopatka, W. Wasik, Przem. Chem., 96, 5 (2017) 